\title{
ARTIGO
}

DOI

\section{O REGIME DE COLABORAÇÃO NA EXECUÇÃO DA POLÍTICA DE FORMAÇÃO DE PROFESSORES DA EDUCAÇÃO BÁSICA}

\author{
THE COLLABORATION SCHEME IN THE IMPLEMENTATION OF THE TRAINING \\ POLICY OF TEACHERS OF BASIC EDUCATION \\ EL RÉGIMEN DE COLABORACIÓN EN LA EXECUCIÓN DE LA POLÍTICA DE \\ FORMACIÓN DE PROFESORES DE LA EDUCACIÓN BÁSICA
}

Cristiane Brito Machado Instituto Federal Baiano - Brasil

Maria Couto Cunha

Universidade Federal da Bahia - Brasil

Gilvanice Barbosa da Silva Musial

Universidade do Estado de Minas Gerais - Brasil

\section{Resumo}

Este artigo tem como objetivo analisar os limites e desafios de se efetivar, no bojo da política nacional de formação de professores da educação básica no Brasil, o regime de colaboração entre os entes federados a partir de uma pesquisa que teve como objetivo investigar a operacionalização do regime de colaboração na implementação do PARFOR Presencial, no estado da Bahia. Apresenta alguns resultados de uma pesquisa desenvolvida durante o Doutorado em Educação que teve como orientação metodológica a pesquisa qualitativa e como principal instrumento de coleta de dados a pesquisa bibliográfica e a entrevista. Inicialmente, tece algumas considerações sobre o federalismo brasileiro, a conceituação do regime de colaboração e as lacunas existentes no cenário nacional por conta da sua não regulamentação. Em seguida, discute os desafios na materialização do regime de colaboração a partir da análise da experiência do PARFOR Presencial na Bahia. Finalmente constata, através dos resultados da pesquisa, a necessidade urgente de que sejam feitos os ajustes necessários na Política estudada, assim como a regulamentação prevista no Artigo 23 da Constituição Federal de 1988 e na institucionalização do Sistema Nacional da Educação, de modo a que os planos, programas e projetos que tenham como premissa a participação compartilhada das instâncias federativas na sua execução obtenham os resultados almejados.

Palavras-chave: Formação de professores. PARFOR. Regime de colaboração. 


\begin{abstract}
This article aims to analyze the limits and challenges of making effective the collaboration regime among federated entities, as part of the national policy of basic education teacher training in Brazil. It was then based on a research that aimed at investigating the operationalization of the collaboration scheme in the implementation of Presential PARFOR, in the State of Bahia. It presents some results from a research developed during the Doctorate in Education that had as a methodological orientation the qualitative research and as the main tool of data collection, bibliographic research and interview. Initially, it makes some considerations about Brazilian federalism, the conceptualization of the collaboration regime and the existing gaps in the national scenario due to its non-regulation. Next, it discusses the challenges in the materialization of the collaboration regime based on the experience of Presential PARFOR in Bahia. Finally, it finds, through the results of the research, the urgency in making the necessary adjustments in the Policy studied, as well as the regulation provided in Article 23 of the Federal Constitution of 1988 and in the institutionalization of the National Education System. In that way, the plans, programs and projects that have as a premise the shared participation of the federative entities in their execution will be able to obtain the desired results.
\end{abstract}

Keywords: Teacher training. PARFOR. Collaborationscheme.

\title{
Resumen
}

Este artículo tiene como objetivo analizar los límites y desafíos de efectivizar, en el seno de la política nacional de formación de profesores de la educación básica en Brasil, el régimen de colaboración entre los entes federados a partir de una investigación que tuvo como objetivo investigar la operacionalización del régimen de colaboración en la implementación del PARFOR Presencial, en el Estado de Bahía. Presenta algunos resultados de una investigación desarrollada durante el Doctorado en Educación que tuvo como orientación metodológica la investigación cualitativa y como principal instrumento de recolección de datos la investigación bibliográfica y la encuesta. En primer lugar, haz algunas consideraciones sobre el federalismo brasileño, la conceptualización del régimen de colaboración y los vacíos existentes en el escenario nacional por su no reglamentación. A continuación discute los desafíos en la materialización del régimen de colaboración desde el análisis de la experiencia del PARFOR Presencial en Bahia. Finalmente constata, desde los resultados de la investigación, la necesidad urgente de que se hagan los ajustes necesarios en la Política estudiada, así como la reglamentación prevista en el Artículo 23 de la Constitución Federal de 1988 y en la institucionalización del Sistema Nacional de Educación, de modo que Planes, programas y proyectos que tengan como premisa la participación compartida de las instancias federativas en su ejecución obtengan los resultados deseados.

Palabras clave: Formación de profesores. PARFOR. Régimen de colaboración. 


\section{Introdução}

Este artigo tem o objetivo de analisar os limites e desafios de se efetivar, no bojo da política nacional de formação de professores da educação básica no Brasil, o regime de colaboração entre os entes federados. Esse regime está inscrito como um princípio constitucional para a execução dos diversos programas elaborados pelo governo, a fim de atender ao que estabelece a legislação e os planos educacionais. Assim, diante da complexidade que envolve a execução dessa política, na qual participam vários órgãos, entidades e instituições de ensino de diferentes naturezas e níveis de poder, com relativos graus de autonomia, tendo como princípio a articulação e negociação em múltiplas situações, perguntamos: quais os limites e desafios para a efetivação do regime de colaboração entre entes federados no processo de desenvolvimento do Plano Nacional de Educação? Quais os impactos da não regulamentação do regime de colaboração nas relações entre os diferentes entes federados no desenvolvimento do referido Programa?

O artigo apresenta uma parte dos resultados obtidos em uma pesquisa maiorl e concentra-se nas ações das representações políticas que compõem o Fórum Estadual Permanente de Apoio à Formação Docente FORPROF, considerando a colaboração esperada entre os entes federados e as instituições de educação superior participantes do PARFOR para a sua implementação.

O texto está assim organizado: inicialmente, tece considerações sobre o federalismo brasileiro e o regime de colaboração, bem como apresenta a própria política de formação em vigência no país. Em seguida, discute os desafios para a materialização do regime de colaboração a partir da análise da experiência do PARFOR Presencial na Bahia. Apresenta alguns

\footnotetext{
${ }^{1}$ A pesquisa analisou o processo de implementação do Plano Nacional de Professores da Educação Básica, no que diz respeito ao PARFOR Presencial, a partir da percepção dos diversos sujeitos, no estado da Bahia, sobre a sua funcionalidade e as possibilidades de alcance dos seus resultados.
} 
resultados da investigação no tocante às dificuldades de articulação e colaboração na execução dessa política, que tem por princípio o regime de colaboração entre os entes federados. Finalmente, tece algumas considerações sobre os achados da pesquisa.

\section{O federalismo brasileiro e o regime de colaboração}

O estudo sobre o regime de colaboração no Brasil não pode deixar de refletir sobre o federalismo como forma de organização do Estado brasileiro presente nesse cenário desde o século XIX. Para Araújo (2010, p.393), "a descentralização desde muito cedo foi assumindo contornos federalistas e depois municipalistas" no país. Cury (2014) ressalta que, com o Ato Adicional de 1834, "houve a adoção de uma descentralização do ensino primário ao atribuir às províncias competência legislativa sobre a instrução pública e estabelecimentos próprios a provê-la". Ressalta que, ainda no regime imperial e centralizado, surge no Brasil "um federalismo educacional e, com ele, uma duplicidade de redes de ensino". (p.26) (grifo do autor)

A Constituição de 1891 instituiu o sistema federativo brasileiro com o objetivo de preservar a unidade territorial, sob o signo de um pacto com as antigas províncias elevadas à categoria de Estados, além de se colocar como resposta à centralização unitária do período colonial e imperial que dificultava o desenvolvimento das bases econômicas e políticas do país. Ao mesmo tempo, manteve quase nos mesmos termos do Ato Adicional acima referido um federalismo educacional, como ressalta Cury (2014).

Para Cury (2006), federação é uma união de membros federados, que forma uma só unidade soberana: o Estado. No regime federal, só há um Estado Soberano, com unidades federadas subnacionais. Estas, por sua vez, gozam de autonomia, cuja relatividade se dá dentro dos limites jurisdicionais atribuídos e especificados. Daí que tais subunidades não são nações independentes nem unidades somente administrativas. 
Costa, Cunha e Araújo (2010, p. 16) consideram que o federalismo se caracteriza como

[...] um pacto de um determinado número de unidades territoriais autônomas com vistas a finalidades comuns. Trata-se de uma organização político-territorial do poder cuja base é a dupla soberania: a dos entes federados (governos subnacionais) e a do governo central (União). Os primeiros têm autonomia para gerir questões locais, e o segundo tem a finalidade de representar e fazer valer os interesses de toda a população do país.

Cury (2006, p. 115) reconhece, no contexto político brasileiro, três tipos distintos em que o federalismo se caracterizou: 1. O federalismo centrípeto se inclina ao "fortalecimento do poder da União, vigente no Brasil entre os anos 1930 e 1980", com especificidades para o período de 1946-1964; 2. O federalismo centrífugo, que consiste no "fortalecimento do poder do Estado membro sobre o da União", presente na Velha República, entre 1898 e 1930; 3. $O$ federalismo de cooperação, que "busca equilíbrio de poderes entre a União e os Estados membros".

A Constituição Federal - CF de 1988 reconhece o Brasil como uma República Federativa formada pela união indissolúvel dos Estados, Municípios e do Distrito Federal. Tal estruturação se faz sob o princípio da cooperação, de acordo com os artigos 1, 18, 23 e 60 da Carta Magna. (BRASIL, 1988)

Por seu turno, o Art. 211 da CF de 1988 determina que "a União, os Estados, o Distrito Federal e os Municípios organizarão em regime de colaboração seus sistemas de ensino", definindo ainda a esfera de atuação de cada ente federativo, ou seja, a responsabilidade de cada um na organização, oferta e atuação, ficando a União incumbida da organização do sistema federal de ensino e também do financiamento das instituições de ensino públicas federais. (BRASIL, 1988).

O Brasil, portanto, segue o modelo cooperativo do federalismo. Para atender a esse modelo federativo e cooperativo, dentre outros modelos de federalismo existentes em outros países, a CF de 1988 fixou um ordenamento 
jurídico no qual coexistem competências privativas, a depender de cada ente federado, competências concorrentes e competências comuns. No Artigo 22 dessa Constituição, são estabelecidas as competências privativas da União, dentre elas a que designa a essa instância de governo o poder de legislar sobre as diretrizes e bases da educação nacional.

A Carta Magna também estabelece, em seu Artigo 25, que os Estados devem ser organizados e regidos pelas constituições e leis que adotarem, desde que respeitada a Constituição Federal. No Artigo 30 dessa lei, são relacionadas as competências privativas dos Municípios, ressaltando, para tanto, a necessidade de articulação destes com a União, os Estados e o Distrito Federal. Com isso, o Inciso VI desse artigo estabelece que o Município deve "manter, com a cooperação técnica e financeira da União e do Estado, programas de educação pré-escolar e de ensino fundamental". (BRASIL, 1988) As competências comuns dos entes federados estão listadas no Artigo 23, destacando a expressa no Inciso $\vee$ que estabelece a incumbência comum de "proporcionar todos os meios de acesso à cultura, à educação e à ciência", cuja cooperação entre as esferas de governo torna-se imprescindível para a sua efetivação. (BRASIL, 1988) A Constituição também fixa competências concorrentes da União, Estados e Distrito Federal, sem incluir aí os Municípios. Em seu Artigo 24, fixa as competências para a União, os Estados e o Distrito Federal legislarem concorrentemente sobre variadas matérias, dentre elas a educação, a cultura, o ensino e o desporto.

Dessa forma, como a educação é responsabilidade de todos os entes federados, ela é matéria concorrencial. O regime de colaboração pressupõe, então, o estabelecimento de normas e finalidades gerais, através de ações articuladas entre eles, em que haja clareza e definição das responsabilidades e competências na prestação dos serviços, neste caso, os educacionais.

Comentando esse sistema, Cury (2006, p. 121-122) afirma que 
A Constituição faz escolha por um regime normativo e político, plural e descentralizado no qual se cruzam novos mecanismos de participação com um modelo institucional cooperativo e recíproco que amplia o número de sujeitos capazes de tomar decisões. Por isso mesmo a cooperação exige entendimento mútuo entre os entes federados e a participação supõe a abertura de arenas públicas de decisão.

No entanto, o federalismo desenvolvido no Brasil e amparado legalmente pela Constituição Federal de 1988 se defronta com a amplitude geográfica, a diversidade econômica e a capacidade de governabilidade que envolve o território nacional. Em diálogo com Almeida (1995) e Soares (1998), Araújo (2010) destaca que "analisar a relação entre o federalismo e o direito à educação implica tomar a descentralização como parâmetro necessário, mas não suficiente". Para a autora, é necessário considerar que "a federação não se caracteriza apenas pela descentralização, supondo-se uma autoridade central, que descentralize ou "recentralize" poderes e atribuições, mas sim pela não-centralização", ou seja, em que "o governo nacional disponha de poder para muitas decisões, mas que não controle todas elas, configurando um compromisso entre difusão e concentração de poder político". (p.232)

Um dos limites para a efetivação do regime de colaboração apontado por Cury (2006) advém da omissão dos parlamentares ao não elaborarem a legislação complementar exigida pela Constituição Federal no parágrafo único do seu Artigo 23. Esse parágrafo estabelece que "Leis complementares fixarão normas para a cooperação entre União, os Estados, o Distrito Federal e os Municípios, tendo em vista o equilíbrio do desenvolvimento e do bem estar em âmbito nacional". (BRASIL, 1988). Outros autores também reconhecem limites na operacionalização do regime de colaboração. Costa, Cunha e Araújo (2010) apontam que as dificuldades enfrentadas relacionam-se diretamente com as questões de maior complexidade, envolvendo a vasta extensão territorial e a existência de grandes desigualdades econômicas, políticas e sociais entre as regiões. 
No que se refere ao primeiro limite acima apontado, estudos tem demonstrado a ausência de interesse por parte dos parlamentares na discussão dessa matéria, a qual levaria ao atendimento do disposto no parágrafo acima mencionado (FERNANDES, 2013). Segundo essa autora, alguns projetos de lei - PL de iniciativa da Câmara dos Deputados têm sido apresentados por parlamentares nesse intuito, os quais, contudo, no curso de suas tramitações, são arquivados. Podemos citar alguns deles: o PL 1946/96 do deputado federal Mauricio Requião; o PL 4553/98, do deputado federal Ivan Valente; o PL 4283/2001, do deputado federal Ricardo Santos; o PL7666/2001, também de iniciativa do deputado Ricardo Santos, com a coautoria do deputado Carlos Humberto Manato; o PL 15/201 1, do deputado federal Felipe Bornier; o PL 5519 de 2013, que propõe a instituição o Sistema Nacional de Educação. Mais recentemente, tivemos o PL 413/2014, do deputado federal Ságuas Moraes, que, como os demais, propôs, dentre outras ações, a organização dos sistemas de ensino e a regulamentação do regime de colaboração entre os entes federados.

O arquivamento desses processos e a ausência de discussão sobre essa matéria no Congresso Nacional têm produzido um vazio de definições e aberto um espaço institucionalizado, inclusive com a participação de setores do governo, como o Conselho Nacional de Educação e o próprio MEC, para o surgimento de ações e proposições, segundo Araújo (2013), que buscam novas formas de colaboração como se fossem sinônimos do regime de colaboração. Segundo essa autora, isso corresponde à tentativa de substituir esse regime pela lógica econômica e neodesenvolvimentista dos arranjos produtivos locais, do protagonismo local e do associativismo voluntário intermunicipal. Dentre essas novas formas de colaboração, a referida autora ressalta os arranjos de desenvolvimento da educação (ADE), os quais são citados inclusive no Parágrafo $7^{\circ}$ do Art. $7^{\circ}$ da Lei 13.005/2014 - lei federal que instituiu o Plano Nacional de Educação. No novo plano decenal da educação, é sinalizado que a adoção desses arranjos deverá levar ao 
fortalecimento do regime de colaboração entre os Municípios. Araújo (2013, p. 799) conclui, em seu artigo:

É exatamente esse o campo de disputa: de um lado os reformadores empresariais defendendo os ADE como sinônimos do regime de colaboração e tentando esvaziar a possibilidade política de sua regulamentação; de outro os profissionais da educação em vários órgãos e instâncias da educação tentando compreender nosso complexo pacto federativo e buscando alternativas de financiamento e possibilidade de fóruns interfederativos que possam se institucionalizar e servir de base para a lei complementar do regime de colaboração que assegure a oferta de educação em quantidade e qualidade com base no princípio da equalização.

É nesse cenário caracterizado pela contingência de consolidar o Sistema Nacional de Educação que nos encontramos. Conforme a Lei 13.005/2014, que aprovou o novo PNE, tal sistema deveria ter sido institucionalizado por legislação própria no prazo de 2 (dois) anos, a partir da publicação do referido plano decenal. Segundo o Art. 13 dessa lei, o Sistema Nacional de Educação seria responsável pela articulação entre os respectivos sistemas de ensino, em regime de colaboração, para efetivação das diretrizes, metas e estratégias desse Plano. (BRASIL, 2014).

Vale lembrar de que as ações, os programas e os projetos operacionalizados pela política educacional atual, sobretudo aqueles coordenados pelo Ministério da Educação, com a participação dos Estados e Municípios, sofrem com as indefinições e incertezas sobre os encaminhamentos a serem adotados para a sua implementação. Isso se deve, entre outras questões, à configuração atual do regime de colaboração, uma vez que este ainda se encontra sem a devida regulamentação. Tal é o caso da política nacional de formação de professores da Educação Básica sobre a qual trataremos a seguir. Buscaremos refletir, então, sobre as dificuldades de articulação entre esses entes federados, entre as diferentes instituições e atores envolvidos no planejamento de suas ações, o que vem comprometendo os seus resultados. 


\section{A formação de professores da educação básica como uma política pública}

No conjunto das políticas educacionais do Brasil, destacam-se aquelas que focalizam a formação do profissional da educação básica, nas últimas décadas, mais especificamente a formação dos professores. Constitui uma prioridade dos governos federal, estaduais e municipais a implantação de programas específicos para atender à demanda de qualificação desses profissionais de modo a contribuir para a melhoria dos processos de ensino.

No bojo dessa política, tem-se observado que setores do governo e da sociedade em geral têm colocado a formação de professores como único elemento em que se deve investir para melhorar a qualidade da educação. É bom observar que outros elementos são essenciais e devem compor uma política geral de apoio aos docentes, incluindo a valorização social da profissão, a melhoria dos seus salários, das condições de trabalho, da infraestrutura das escolas, das formas de organização do trabalho escolar e, enfim, a valorização da carreira docente. Esses elementos devem fazer parte da política geral de apoio aos docentes (GATTI, BARRETO e ANDRÉ, 2011, p.15).

Gatti (2011), ao tratar da questão docente, aponta que, hoje, em função de graves problemas que enfrentamos em relação às aprendizagens escolares, aumenta-se a preocupação com a qualidade do ensino dos cursos de licenciatura. A autora destaca que os problemas de aprendizagem não estão apenas ligados ao desempenho pedagógico do professor, mas, também, estão associados a outros fatores como

[...] as políticas educacionais postas em ação, o financiamento da educação básica, aspectos das culturas nacional, regionais e locais, hábitos estruturados, a naturalização da nossa sociedade da situação crítica das aprendizagens efetivas de amplas camadas populares, a forma de estrutura e gestão das escolas, formação dos gestores, as condições sociais e de escolarização dos pais e 
mães de alunos das camadas populacionais menos favorecidas (2011, p. 205).

Mesmo considerando esses fatores, entretanto, é necessário que se dê uma atenção especial para a questão da formação inicial dos professores, sobretudo na educação básica. Gatti (2011) propõe 'virar a mesa', com políticas corajosas, deixando de lado experiências de pequeno porte, as quais dificilmente redundarão em mudanças para o imenso e disperso universo das escolas municipais e estaduais espalhadas no país, com a melhoria da qualidade na formação desses profissionais para propiciar melhores oportunidades formativas para os alunos.

Na defesa dessa formação, Gatti (2011, p. 206) pensa o professor como um profissional que deve estar preparado para enfrentar os desafios frequentes do seu cotidiano de trabalho. Mesmo considerando que o curso de graduação não forma completamente um profissional, esse curso deve oferecer uma formação básica adequada para que o professor possa desenvolver o seu trabalho com condições de atuar e sempre aperfeiçoarse a partir dessa base formativa.

É importante salientar que a história da formação de professores do ensino básico no Brasil passa a ter maior ênfase a partir do processo de expansão da escolarização no país, principalmente quando os contingentes das classes populares adentraram às escolas nas últimas décadas do século XX. Em 1970 e início dos anos 1980, foi quando começou o crescimento real nas redes públicas de ensino, considerando o número de matriculados no ensino fundamental, proporcionalmente ao contingente de crianças e adolescentes na faixa etária correspondente ou próxima da ideal. (GATTI e BARRETO, 2009)

A partir dessa expansão, intensificaram-se as discussões sobre a formação de professor, assim como os movimentos para normatizar esse processo a partir da legislação. A LDB n 9394 de 1996 estabeleceu a preferência do nível superior para a formação de professores da Educação Básica, no seu artigo 62. Tal preferência, entretanto, apresentava-se 
ambiciosa diante da realidade da educação do Brasil, pois a grande maioria dos professores que atuavam na educação básica não possuía a formação indicada por essa legislação. Para o magistério da educação infantil e das quatro primeiras séries do ensino fundamental, o Art. 62 da LDB admitia formação em nível médio, porém, também é colocado nessa lei, no $4^{\circ}$ parágrafo do Art. 87 das Disposições Transitórias, que, "até o fim da Década da Educação somente serão admitidos professores habilitados em nível superior ou formados por treinamento em serviço". (BRASIL, 1996, p. 30)

Deve-se acrescentar que, mesmo respaldada legalmente essa formação de nível superior para os professores e apesar da implantação de programas e ações nessa direção, os dados recentes sobre o nível de formação dos docentes no Ensino Fundamental e médio não apontam bons resultados.

Conforme o censo escolar de 2015, dos 2.187.1542 docentes que atuavam na educação básica do país, $28 \%$ não possuíam a formação adequada. Nesse número, incluem-se professores sem nível superior ou formados em outras áreas, como engenharia, saúde, administração, etc. Quando analisamos esses mesmos indicadores para a região Nordeste, o percentual de professores sem formação adequada chega a 39,6\% e, para o estado da Bahia, chega a 41,3\%. (BRASIL/MEC/INEP, 2015).

De acordo com esses dados, é possível verificar que, após mais de vinte anos, a lei ainda não está sendo cumprida, quanto ao nível de formação dos professores para atuar na educação básica. O censo escolar de 2015 aponta a necessidade de qualificar mais de 600 mil professores brasileiros que ainda não têm a formação requerida para o exercício da docência na educação básica. Desse total, mais de 200 mil estão na região Nordeste do país e 64 mil no Estado da Bahia.

\footnotetext{
2 Vale ressaltar que o indicador é calculado com base na função docente. Portanto, um professor poderá ser contabilizado mais de uma vez no total se tiver mais de um cargo de professor. Para cada função docente, verifica-se se o professor tem educação superior e, no cálculo das desagregações, se ele tem ou não licenciatura. O percentual é calculado em relação ao total de funções docentes.
} 
Os programas de governo voltados para a formação de professores da educação básica em nível superior, nesse contexto de implementação de políticas públicas de educação, concretizaram-se no início do século XXI, através de um conjunto de medidas adotadas pelo Governo Federal. Em 2007, a Presidência da República lançou o Plano de Metas Compromisso Todos pela Educação, através do Decreto 6.094, que dispõe sobre a implementação dessas metas pela União Federal, em regime de colaboração com os entes federados e a participação das famílias e da comunidade, mediante programas e ações de assistência técnica e financeira, visando à mobilização social pela melhoria da qualidade da educação básica (BRASIL, 2007a). Dentre as diretrizes deste Plano, é definida, no inciso XII do decreto, a instituição de programas para formação inicial e continuada de profissionais da educação.

Para cumprir o Plano de Metas do Compromisso Todos pela Educação, - Decreto 6094 também regulamentou os Planos de Ações Articuladas (PAR) no seu artigo $9^{\circ}$, estabelecendo que "O PAR é o conjunto articulado de ações, apoiado técnica ou financeiramente pelo Ministério da Educação, que visa ao cumprimento das metas do Compromisso e a observância das suas diretrizes". (BRASIL, 2007a) O PAR, instrumento de planejamento a ser adotado pelos Estados, Distrito Federal e Municípios, tem a finalidade de refletir sobre as necessidades e aspirações desses entes federados, em termos de ações, demandas, prioridades e metodologias. No que diz respeito ao magistério, é previsto o diagnóstico sobre a necessidade de qualificação dos profissionais da educação, visando a assegurar a formação exigida na LDB para todos os professores que atuam na educação básica, sendo que a formação inicial de professores em exercício das redes públicas torna-se uma prioridade, fazendo parte de uma das quatro dimensões estruturadas para a elaboração desse instrumento de planejamento em cada uma das instâncias de governo.

O Ministério da Educação - MEC, nesse mesmo ano de 2007, lançou o Plano de Desenvolvimento da Educação - PDE, que consistiu, segundo esse 
Ministério, em um conjunto de ações estruturadas baseado nos princípios da educação sistêmica, com ordenação territorial, a fim de diminuir as desigualdades regionais e sociais. Esse plano foi baseado em quatro eixos articuladores: Educação Básica; Alfabetização, Educação Continuada e Diversidade; Educação Tecnológica e Profissional e Educação Superior. No eixo Educação Básica, a formação de professores figura como um dos principais pontos indicados no PDE, então colocada como "urgente, estratégica que reclama resposta nacional" (BRASIL, 2007b, p.15).

Muitas ações nesse sentido foram implementadas pela União. No cenário de dispersão e fragmentação dessas políticas, o governo federal propôs, a partir daí, articular suas ações e formular uma política nacional de formação para professores da educação básica. O objetivo era colocar em prática o que determina a LDB 9394, de 1996, no que se refere à formação inicial em nível superior dos professores. Com isso, o MEC, nos últimos anos, vem implementando uma política ordenada nessa direção, a qual é orientada na perspectiva da instituição de um sistema nacional de educação que, segundo Gatti, Barreto e André,

[...] traduz o avanço do processo de responsabilização do poder público pelo desempenho e pela carreira dos professores da educação básica e considera a formação como um processo contínuo de construção de uma prática docente qualificada e de afirmação da identidade, da profissionalidade e da profissionalização dos professores. (GATTI, BARRETO, ANDRÈ, 2011, p.49)

Para a efetivação dessa política, foi aprovada a Lei $n^{\circ} 11.502$, de 11 de julho de 2007, que ampliou o papel da Coordenação de Aperfeiçoamento de Pessoal de Nível Superior (CAPES) do Ministério da Educação, anteriormente responsável pelo aperfeiçoamento do pessoal docente de nível superior das instituições públicas. A partir desta Lei, a CAPES passou a ser responsável, também, pela formação de professores da educação básica. Em termos concretos, o Decreto Presidencial n 6755, de 2009, instituiu a Política Nacional de Formação de Profissionais do Magistério da Educação 
Básica, disciplinando a atuação da CAPES, em regime de colaboração com os entes federados, no fomento a programas de formação inicial e continuada do magistério das redes públicas da educação básica. As ações foram destinadas, prioritariamente, para a formação de professores em exercício, como é o caso do Plano Nacional de Formação dos Professores da Educação Básica - PARFOR, que foi lançado em maio de 2009 e tem o objetivo de melhorar a formação dos docentes das redes públicas ${ }^{3}$. (BRASIL, 2009)

O PARFOR foi implantado para proporcionar o oferecimento de cursos de graduação para educadores em exercício no magistério público que estão em uma das três situações seguintes: professor que ainda não tem curso superior; professor com licenciatura, mas que leciona em área diferente daquela em que se formou; bacharel em exercício da docência na rede pública de educação básica sem licenciatura, que precisa de estudos complementares que o habilite ao exercício do magistério. Foi proposto que a CAPES gerenciasse e acompanhasse o processo de proposição, inscrição e execução dos planos estratégicos dos Estados, em parceria com as Instituições de Educação Superior (IES), sendo que os cursos disponibilizados poderiam ocorrer na modalidade a distância (com a oferta feita pela Universidade Aberta do Brasil) ou presencial, com a abertura de cursos específicos mediante articulações feitas com as Instituições de Educação Superior. A essa última modalidade, portanto, convencionou-se denominar de PARFOR Presencial.

O decreto 6755/09 estabeleceu, ainda, para a implementação dessa política, a existência dos Fóruns Estaduais Permanentes de Apoio à Formação Docente - FORPROF em cada Estado da federação, compostos por representações dos setores do governo e da sociedade civil, incumbidos de dar apoio, deliberar sobre decisões necessárias para o andamento das

\footnotetext{
${ }^{3}$ Recentemente o Decreto $n^{\circ} 8752 / 2016$ dispõe sobre uma nova política de formação, desta vez para os profissionais da educação básica, com avanços e maior abrangência de suas ações, indicando preocupação com a qualificação dos outros profissionais da escola, além da docência, de modo a elevar a qualidade do ensino oferecido e promover a valorização desses profissionais. (BRASIL, 2016)
}

Revista Práxis Educacional, Vitória da Conquista - Bahia - Brasil, v. 14, n. 27, p. 33-59, jan./mar. 2018. 
ações de formação, na intenção de facilitar a interação entre os agentes responsáveis por tais ações. A composição desse Fórum indica a participação dos entes federados, das instituições de ensino superior que ofertam os cursos, de entidades da sociedade civil ligadas ao tema, o que reforça o compromisso de acompanhar o desenvolvimento da política, seguindo o princípio constitucional do regime de colaboração.

Deve-se salientar que os componentes do FORPROF estão ligados à implementação das ações da política não apenas nos espaços do Fórum, mas, também, nas suas unidades de representação. No caso do PARFOR Presencial, pode-se dizer que as Universidades Estaduais e Federais e os Institutos Federais de Educação ficam responsáveis pela oferta dos cursos; as Secretarias de Educação dos Municípios e dos Estados são as responsáveis por promover e facilitar a participação dos professores-estudantes no curso; a CAPES fica responsável pelo repasse dos recursos, pelo gerenciamento e pela coordenação da política. Ainda existem responsabilidades que são coletivas, como a de planejar estrategicamente as ações, acompanhar e avaliar a política, divulgar as ações, dentre outras atribuições.

É importante refletir sobre os desafios, tensões e possibilidades existentes nesse cenário da gestão dessa política, com a existência dessa diversidade de funções e responsabilidades compartilhadas. Não há como negar que o envolvimento de várias instituições, como: MEC, através da CAPES, Universidades e Institutos, Prefeituras Municipais, secretarias de educação estaduais e municipais e escolas constitui-se como um processo bastante complexo, que têm desdobramentos variados a depender das configurações em cada estado, em cada município, levando em conta uma política de âmbito nacional, mesmo que as regras da política estejam padronizadas. Para melhor compreender a operacionalização dessa política, faz-se necessário observar, principalmente, a atuação dos vários setores, considerando que o regime de colaboração entre os entes federados é pressuposto e fator importante para o alcance dos resultados. 
Levando-se em conta, portanto, que essa política de formação de professores da educação básica está inserida nesse contexto, torna-se relevante analisar a adequação das medidas tomadas como estratégias e ações para a implementação do PARFOR no Estado brasileiro, tanto por meio dos seus fóruns, como através dos outros atores envolvidos na realização da política. Torna-se importante verificar de que maneira ocorrem as inter-relações entre os órgãos, entre as instituições e os sujeitos participantes dessa política para o alcance dos objetivos e metas do Plano.

\section{O regime de colaboração na materialização da política de formação de professores da educação básica}

Faz-se aqui uma análise dos resultados do estudo empírico, com informações coletadas através de entrevistas aos componentes do FORPROF do Estado Bahia, investigando a percepção dos participantes desse Fórum na programação das ações, quando pretendem identificar a demanda de formação dos professores em exercício da educação infantil e dos anos iniciais do ensino fundamental das redes públicas do estado, aqueles que não possuem curso de nível superior. Em seguida, analisa os entraves e desafios sentidos por esses informantes para que se desenvolva nesse cenário o planejamento da oferta de cursos e a divulgação dessa oferta para o público alvo - os professores e para os sistemas de ensino.

Como já acentuado, o Fórum tem um papel relevante na implantação e desenvolvimento da política de formação de professores da educação básica no Estado. Para tanto, é essencial que seja procedida a identificação das necessidades de formação desses profissionais para atender aos sistemas de ensino, daí a importância de se realizar o diagnóstico dessas necessidades através da elaboração e atualização constante de um plano estratégico. Sobre essa questão, os dados da pesquisa constataram que o Fórum da Bahia não possuía no momento da coleta de dados da pesquisa 
um plano estratégico de ação definitivo e atualizado para a formação de professores em serviço no estado.

Algumas tentativas foram realizadas para a construção desse plano, buscando a colaboração das instituições: foram levantados dados estatísticos nas agências oficiais, como no INEP, para verificar a demanda por formação e foram feitos levantamentos a partir de informações dos próprios sistemas de ensino. No entanto, verificou-se a ausência de um banco de dados confiável. Segundo os informantes, os dados disponibilizados pelo INEP sobre formação de professores apresentavam alguns problemas: nem todos os professores das redes, sobretudo as municipais são efetivos; muitos são professores prestadores de serviço com contratos temporários e precários que, por isso, nem sempre são incluídos nos censos escolares. Além disso, os dados do INEP classificam os docentes na categoria de funções docentes, o que significa que pode contabilizar cada professor em cada um dos vínculos que possuem. Muitos professores trabalham em duas e até três redes de ensino ou tem mais de uma função no mesmo sistema de ensino e essas situações não são identificadas na base de dados do INEP. Esse fato, portanto, superdimenciona o quantitativo de professores existentes. Caso os estados e os municípios não possuam um banco de dados específico considerando a caracterização do seu corpo docente, o mapeamento das necessidades de formação poderá ficar comprometido, se somente é utilizada a fonte de dados do INEP que, embora importante, não é suficiente. Com isso, o Fórum, que reúne representantes dos vários segmentos institucionais, não consegue ter um diagnóstico real dessas necessidades.

A fala de um entrevistado ilustra essa dificuldade, quando ele sugere que esse processo deve ser aprimorado a partir de dados que os municípios necessitam levantar sobre as suas próprias redes. Ele considera que os dirigentes e técnicos municipais não contam com informações seguras sobre as suas próprias demandas e nem mostram interesse para aproveitar as 
oportunidades de formação de seus professores. Literalmente este entrevistado informa:

Acho que os municípios, não sei porque, ou são céticos quanto ao significado da formação para a melhoria da qualidade [do ensino] ou porque, de fato, os municípios não estão tão interessados na qualidade. Eles estão ainda naquela lógica de atender a todos, mas não exatamente atender a todos com qualidade. Eu diria, portanto, que são metas quantitativas, mas sem nenhum horizonte em termos de qualidade. Não vejo essa preocupação. (MF2)

Representantes das instituições de educação superior que participam do Fórum também fazem críticas aos procedimentos da definição da demanda de formação para o PARFOR Presencial no Estado, realizados pelo Fórum. Para um deles, um problema detectado corresponde à variedade de fontes desses dados para ser levantada a demanda real. Segundo ele, "nesse ponto a gente enfrentou vários, vários problemas porque desde 2009 , desde seu início, a demanda não tem sido qualificada, acho que nunca foi qualificada". (MFI2) Em alguns casos, são considerados os dados do Educacenso, em outros, tomam-se como parâmetro as cobranças dos municípios a partir do diálogo com os seus representantes, ou seja, não se consegue ter parâmetros seguros para caracterizar as necessidades de formação.

Um dos coordenadores institucionais do PARFOR Presencial nas universidades e membro do Fórum salienta a imprecisão na identificação da real demanda. Para ele, estas informações, quando são fornecidas pelos sistemas de ensino nem sempre correspondem ao objetivo fim da política, nem aos dados oficiais, uma vez que existem nesses levantamentos professores contratados temporariamente e que não são considerados demanda real para esses cursos.

Esse mesmo informante aponta que existem interesses políticos nas indicações dessas demandas, de forma que constituem informações sem bases estatísticas e que servem a interesses partidários. Em conclusão sobre 
esse aspecto, a pesquisa detectou questões ligadas à imprecisão dos bancos de dados, sendo as informações coletadas com o INEP e as prestadas pelos municípios sobre suas demandas não correspondentes às reais necessidades, o que leva a apresentar uma demanda aleatória, em alguns casos, motivada por interesses políticos, conforme alguns entrevistados. Um dos entrevistados ilustrou esta questão:

[...] O Fórum solicitou aos secretários a demanda, eles, a grande maioria dos secretários, informam um número de professores que eles querem informar no município, porque é por questões políticas. Um município, por exemplo, que tinha uma escola de $5^{a}$ à $8^{a}$ série solicitou 20 professores de língua portuguesa, 15 professores de geografia. Então, a gente não precisa fazer uma pesquisa no município pra saber que eles querem informar a demanda social ${ }^{4}$, que aquelas pessoas não são efetivas. (MFI2)

Todos esses problemas acarretam dificuldades na formação das turmas para os cursos e deixam todo o processo mais lento e pouco efetivo. Tais dificuldades sentidas no planejamento das ações de implementação do programa denotam os impasses pela falta de se estabelecer o chamado regime de colaboração entre os entes federados, já no planejamento das ações, dada a complexidade das relações envolvendo várias instâncias e órgãos. Em nosso entendimento, esse é um ponto de tensão na condução da política de formação de professores, público alvo do PARFOR Presencial. Desse modo, os resultados das atividades voltadas à previsão de necessidades se encontram comprometidos para um desenvolvimento adequado da política.

A falta, portanto, de orientações e do estabelecimento de regras, conforme previsto na Constituição Federal, em termos da articulação necessária entre os entes federados quando na realização de ações comuns, regulamentação que poderia ser fixada pela legislação complementar sobre o regime de colaboração, conforme foi mencionado

\footnotetext{
4 Demanda social corresponde a cota de participantes dos cursos que não são professores da Rede.
} 
no início deste texto, de fato, provoca ineficiência no desenvolvimento das ações dessa política, contribuindo para o comprometimento dos seus resultados.

No que diz respeito à necessidade de ajustar as informações sobre as demandas dos sistemas de ensino com as possibilidades de oferta de cursos de formação, os dados da pesquisa mostraram que, nem sempre, as IES podem se responsabilizar por abrir os cursos solicitados para atender à demanda detectada. Por outro lado, existem situações em que aparece a oferta de cursos por parte das instituições, mas os professores das redes de ensino não se inscrevem para fazer os mesmos. Noutras situações, ainda, instituições de educação superior oferecem os mesmos cursos nas mesmas localidades, o que leva a desperdícios e ao baixo número de matrículas nessas iniciativas. Por conseguinte, nem sempre a necessidade de formação se relaciona com as possibilidades de oferta dos cursos. Assim, o processo de comunicação entre redes de ensino e instituições de educação é fragilizado. A articulação entre os entes federados e as instituições nem sempre acontece de forma adequada para programar com sucesso as ações do Plano.

Em outra vertente de análise, com os dados das entrevistas, percebese que os nossos informantes colocam a colaboração institucional entre os entes federados e as demais instâncias do programa como imprescindível, mas é demonstrado, também, que ela, sozinha, não é suficiente, pois faltam condições reais de oferta. A compatibilização entre estes dois termos: demanda e oferta se inviabiliza pela concorrência de variados fatores, dificultando o desenvolvimento de uma política, que tem como princípio a cooperação.

Sobre a necessidade de divulgação da oferta de formação do Plano, depois de definida a programação, para que os professores das redes de ensino se inscrevam nos cursos, que é atribuição do Fórum na condução da política, os dados constatados nas entrevistas deram conta da ocorrência de alguns equívocos que levaram a problemas de identificação do real 
público a ser atendido e sobre a concepção da própria política. Pelo menos, dois integrantes do Fórum consideraram a divulgação restrita. Um deles salientou que o governo federal fez uma grande propaganda no inicio do PARFOR Presencial que não alcançou o verdadeiro objetivo. As críticas se referem a uma grande parte do público que foi estimulado pela divulgação, mas que não se constituía demanda para essa formação, muitos não eram professores das redes públicas. Um informante especificou melhor esses equívocos:

[...] todo mundo que queria ser professor na rede pública estadual ou municipal correu e fez a pré inscrição, não ficou claro que esse programa era específico para professores que estavam em sala de aula. Eu me refiro especificamente às inscrições feitas por merendeiras, pelos porteiros, pelos vigilantes. (MFI3)

Nos anos subseqüentes ao da criação do PARFOR, essa divulgação passou a ser feita de forma mais qualificada, na opinião dos informantes. No entanto, no caso analisado, há uma imprecisão com relação à responsabilidade dessa divulgação. Alguns membros do Fórum consideram que a responsabilidade deve ser do governo federal e dos dirigentes do Fórum, como instância de decisão sobre a condução da política no Estado e não consideram que tal tarefa seja das instituições que representam. É importante ressaltar o que chama a atenção um dos membros do Fórum sobre as limitações do uso dos meios de comunicação de massa nessa divulgação para determinadas regiões e para determinadas categorias de professores que não dispõem de recursos midiáticos. Sua crítica se baseia no fato de que nem sempre esses recursos de comunicação mais sofisticados atingem a grande parte dos professores do interior do estado que necessitam dessa formação. Assim se expressou a entrevistada:

A divulgação entende que todos estão expostos à mídia, digamos, de massa, o que não é exatamente verdade, quando você trata [das cidades] do interior, que às vezes recebem o sinal por antena parabólica e as propagandas não 
entram. Então essa divulgação precisava ser melhor estudada. (MF2)

A partir da fala dos colaboradores da pesquisa, fica claro que a divulgação da programação dos cursos ainda tem muitas falhas, que vão, desde a escolha dos meios de comunicação à falta de clareza na definição de quais são os responsáveis por esse processo no programa. Porém, os membros reconhecem a importância de divulgar, de buscar meios para atingir o público alvo.

\section{Considerações preliminares}

A pesquisa empreendida constatou as dificuldades de articulação e colaboração na execução de uma política que tem por princípio o regime de colaboração entre os entes federados. No PARFOR Presencial do Estado da Bahia, foram identificados alguns problemas para a sua concretização, a partir dos relatos dos informantes: ausência de um banco de dados adequado e atualizado para o mapeamento da demanda de professores em exercício, sem a formação em nível superior; rotatividade contratual dos professores com a grande presença de professores temporários nos sistemas municipais de ensino, o que dificulta identificar a demanda real; desvio dos verdadeiros objetivos do Plano, uma vez que se constatou a presença de interesses político-partidários na indicação de pessoas para frequentar os cursos; falta de registro e levantamento de dados por parte dos sistemas de ensino sobre a quantidade de professores que necessitam de formação; dificuldades de disponibilização da oferta de determinados cursos pelas IES, por variadas razões internas ao seu funcionamento; dificuldades de divulgação da programação dos cursos para os professores e para os sistemas de ensino sobre as possibilidades de formação.

Muitos desses problemas podem ser analisados a partir da fragilidade do regime de colaboração em operação nessa política, conforme apontam alguns autores (CURY, 2006 e ARAÚJO, 2010). Há que se ressaltar a ausência 
de uma cultura de colaboração efetiva no serviço público no Brasil. A dificuldade de diálogo entre os atores envolvidos, a falta de clareza na definição das responsabilidades de cada ente na execução da política e a burocratização dos processos, entre outros, mostraram ser fatores impeditivos para o sucesso das atividades do programa analisado.

Apesar desses problemas, o Fórum foi considerado, pelos entrevistados, como um espaço de grande importância para atender aos objetivos da política de formação de professores estabelecida. A participação de vários atores permitiu um diálogo mais frequente, além de contribuir para a troca de experiências entre as instâncias em que ocorrem as discussões para possíveis articulações entre programas do governo. Sendo assim, o Fórum pode ser considerado um bom começo para se conseguir a cooperação desejada entre as instituições envolvidas na política e um passo importante para o aprimoramento do regime de colaboração.

Mesmo ao analisar esse caso particular, pois diz respeito à realização de um programa em uma unidade da federação, os resultados dos seus estudos corroboram para as reflexões tecidas no início deste artigo sobre a necessidade urgente de que sejam estabelecidas as regras para a efetivação do regime de colaboração entre os entes federados quando em desenvolvimento de ações comuns. No caso da área educacional, na iminência de se constituir formalmente o Sistema Nacional de Educação com data precisa para ocorrer, conforme estabelece o PNE/2014, os parlamentares necessitam se debruçar sobre essa matéria, para que as políticas educacionais possam ser implementadas, quando programadas com a participação na perspectiva federalista, conforme o Estado de Direito que a Constituição Federal de 1988 consagrou para o Brasil.

\section{Referências}

ARAÚJO, Gilda Cardoso de. Direito à educação básica: A cooperação entre os entes federados. Retratos da Escola, Brasília, v. 4, n. 7, p. 231-243, jul./dez. 2010. Disponível em: http//www.esforce.org.br. Acesso em: 09 de março de 2017. 
ARAÚJO, Gilda Cardoso de. Federalismo e políticas educacionais no Brasil: equalização e atuação do empresariado como projetos em disputa para a regulação do regime de colaboração. Educação e Sociedade, Campinas. v. 34, n. 124, p. 787-808, jul./set. Campinas, 2013.

ALMEIDA, Fernanda Dias Menezes. Competências na Constituição de 1988. 3. ed. São Paulo: Atlas, 2005.

BRASIL. Constituição da República Federativa do Brasil 1988. Salvador: Empresa Gráfica da Bahia, 1988.

BRASIL. Lei de Diretrizes e Bases da Educação Nacional: Lei n. 9.394, de 20 de dezembro de 1996. Estabelece as Diretrizes e Bases da Educação Nacional. 8.ed.Brasília: Câmara dos Deputados, Edições Câmara, 2013.

BRASIL. Plano de Desenvolvimento da Educação: razões, princípios e programas, 2007a. Disponível em:

<http//www.portal.mec.gov.br/arquivos/livro.pdf> Acesso em: outubro de 2014.

BRASIL. Decreto $n^{\circ}$ 6.094. Dispõe sobre a implementação do Plano de Metas Compromisso Todos pela Educação, 2007b. Disponível em:

http://planalto.gov.br/ccivil 03/ato2007-2010/2007/decreto/d6094.htm.

Acesso em outubro de 2014.

BRASIL. Decreto $n^{\circ}$ 6.755, de 29 de janeiro de 2009. Institui a Política Nacional de Formação de Profissionais do Magistério da Educação Básica, disciplina a atuação da Coordenação de Aperfeiçoamento de Pessoal de Nível

Superior, e dá outras providências. Brasília/DF: MEC, 2009. Disponível em:

http://www.planalto.gov.br/ccivil_03/_ato2007-

2010/2009/decreto/d6755.htm. Acesso em: março de 2016.

BRASIL. Decreto $\mathbf{n}^{\circ} \mathbf{8} . \mathbf{7 5 2}$ de 09 de maio de 2016. Dispõe sobre a Política Nacional de formação dos Profissionais da Educação Básica. Brasília/DF: 2016. Disponível em: www.planalto.gov.br/ccivil 03/ Ato20152018/2016/Decreto/D8752.htm. Acesso em março de 2016.

BRASIL. Lei 13.005 de 25 de junho de 2014. Aprova o Plano Nacional de Educação - PNE e dá outras providências. 2014. Disponível em:

fne.mec.gov.br/. Acesso em fevereiro de 2015.

BRASIL/MEC/INEP. Censo Escolar: Sinopse Estatística da Educação Básica,

2015. Disponível em: http://portal.inep.gov.br/web/guest/sinopsesestatisticas-da-educacao-basica Acesso em: 20 de março de 2017. 
COSTA, Jean Mário Araújo; CUNHA, Maria Couto, ARAÚJO, Rosimeire Moura de. Federalismo cooperativo brasileiro: implicações na gestão da educação municipal. Jornal de Políticas Educacionais, N 8, Jul.-Dez. de 2010, pp. 14-23

CURY, Carlos Roberto Jamil. Federalismo político e educacional. In: FERREIRA, NauraSyriaCarapeto (Org.) Políticas públicas e gestão da educação. Brasília: Liber Livro, 2006.

CURY, Carlos Roberto Jamil. Educação e direito à educação nas constituições brasileiras. Belo Horizonte: Mazza Edições, 2014. 80p.

FERNANDES, Thmyres Wandel Pol. Sistema Municipal de Educação de Juiz de Fora: as interfaces dos caminhos da cooperação e colaboração. 2013. $195 f$. Dissertação de Mestrado, Faculdade de Educação da UFJF. Juiz de Fora, 2013.

GATTI, Bernadete Angelina; BARRETO, Elba Siqueira de Sá. Professores no Brasil: impasses e desafios. Brasília: UNESCO, 2009.

GATTI, Bernadete Angelina; BARRETO, Elba Siqueira de Sá; ANDRÉ, Marli Eliza Dalmazo de Afonso. Políticas docentes no Brasil: um estudo da arte. Brasília: UNESCO, 2011.

GATTI, Bernadete Angelina. A questão docente: formação, profissionalização, carreira e decisão política. In: GARCIA, Walter E. (Org.) Bernadete A. Gatti: educadora e pesquisadora. Belo Horizonte: Autêntica, 2011.

SOARES, Márcia Miranda. Federação, democracia e instituições políticas. Lua Nova, São Paulo, n. 44, 1998.

\section{SOBRE AS AUTORAS:}

\section{Cristiane Brito Machado}

Doutora em Educação, pela Universidade Federa da Bahia (UFBA); professora do Instituto Federal de Educação, Ciência e Tecnologia Baiano (IFBaiano); membro do Grupo de Política e Gestão da Educação da UFBA. Email: cristianeufba@yahoo.com.br

\section{Maria Couto Cunha}

Doutora em Educação, pela Universidade Federa da Bahia (UFBA); professora do Programa de Pós-graduação em Educação da UFBA; membro do Grupo de Política e Gestão da Educação da UFBA. Email:mariacoutocunha@gmail.com 


\section{Gilvanice Barbosa da Silva Musial}

Doutora em Educação, pela Universidade Federa de Minas Gerais (UFMG); professora do Programa de Pós-Graduação em Educação da Universidade do Estado de Minas Gerais (UEMG); membro do Grupo de Política e Gestão da Educação da UFBA e do Grupo de Pesquisa e Extensão em Educação de Jovens e Adultos UEMG. E-mail: gilvanice.musial@ufba.br

Recebido em: 28 de maio de 2017. Aprovado em: 28 de junho de 2017. 